\title{
Liver disease in a district hospital remote from a transplant centre: a study of admissions and deaths
}

\author{
M H Davies, M J S Langman, E Elias, J M Neuberger
}

\begin{abstract}
The profile of liver disease admissions and associated deaths in a district general hospital was studied to determine whether patients with end stage liver disease are appropriately referred for consideration of liver transplantation. Admission details were provided by the Office of Population Censuses and Surveys (OPCS) and their accuracy was assessed by case note analysis. According to OPCS, 77 patients with liver disease were admitted on 113 occasions between 1 January 1987 and 31 December 1989. The case notes of $74(96 \%)$ were retrieved and examined. Only $64(86 \%)$ had primary liver disease. Twenty four (31\%) died of liver failure. Alcohol was the aetiological agent in two thirds. According to accepted criteria, 11 patients were suitable for liver transplant assessment but only three had been referred to a transplant centre. Of the remaining eight, five died during the study period. Two of the three patients referred died without transplantation; one underwent transplant and survived. There is discrepancy between OPCS data and true disease aetiologies, with approximately $\mathbf{4 0 \%}$ under reporting of alcoholic liver disease. If this population is representative of the situation nationally, substantial numbers of patients with end stage liver disease might benefit from liver transplantation, but are not referred to a centre.
\end{abstract}

(Gut 1992; 33: 1397-1399)

Liver transplantation has been gaining increasing support as a means of treating chronic end stage liver disease ${ }^{12}$ and fulminant hepatic failure. ${ }^{3}$ Improved survival and excellent rehabilitation subsequent to liver transplantation $^{4}$ have led to rapid and considerable expansion of the transplant programme in the United Kingdom and elsewhere.

Indications for liver transplantation have changed. For example, long term results in patients with cholangiocarcinoma ${ }^{5}$ and hepatitis $\mathrm{B}$ infection ${ }^{67}$ have been disappointing, because of a high rate of disease recurrence. In contrast, selected patients with alcoholic liver disease frequently fare well and are likely to represent an increasing population of transplant candidates. ${ }^{8}$ The guidelines are now more precisely defined and have been described in detail elsewhere. ${ }^{29-11}$

It has proved difficult to determine how many patients in the UK might benefit from liver transplantation. This information is of great importance in planning national transplant services. One method of assessing need is to use mortality statistics collected by the Office of Population Censuses and Surveys (OPCS). However, even if the ascribed causes of death are correct, these data do not indicate those patients who are potential transplant candidates.

To try to decide how many patients might be suitable for transplantation, an audit was performed of admissions to a district general hospital of patients with end stage liver disease. This also enabled us to examine the accuracy of OPCS data concerning the diagnosis of liver disease.

\section{Methods}

The hospital was selected because it is remote from a transplant centre and its geographical location dictates that virtually all medical emergencies and outpatient referrals are sent there. The hospital has four consultant physicians, one with a special interest in gastroenterology. The area served by the hospital, situated in South Wales, has a static population of 180000 , comprising both urban and rural communities.

After permission had been obtained for access to medical records, the OPCS provided details of all admissions to this hospital with various liver diseases (diagnoses listed in Table I) for the three years from 1 January 1987 (the most recent dates available).

Case records were retrieved and examined to established if these patients would have been suitable for transplant assessment, ${ }^{29-11}$ either on the basis of poor quality of life or expected survival, in the absence of transplantation, of less than one year. Clinical indications included encephalopathy, recurrent variceal haemorrhage unresponsive to therapy, repeated episodes of bacterial peritonitis or intractable ascites. Bio-

TABLE I Spectrum of liver disease admissions requrested via Office of Population Censuses and Surveys (OPCS): Fanuary 1987-December 1989

\begin{tabular}{ll}
\hline$I C D^{\star}$ & Description \\
\hline 571.0 & Alcoholic fatty liver \\
571.1 & Acute alcoholic hepatitis \\
571.2 & Alcoholic cirrhosis of liver \\
571.3 & Alcoholic liver disease \\
453.0 & Budd-Chiari syndrome \\
570.0 & Acute/subacute liver necrosis \\
571.4 & Chronic hepatitis \\
571.5 & Cirrhosis, no mention of alcohol \\
571.6 & Biliary cirrhosis \\
571.8 & Chronic non-alcoholic liver disease \\
571.9 & Unspecified non-alcoholic liver disease \\
572.2 & Hepatic coma \\
572.3 & Portal hypertension \\
572.4 & Hepatorenal syndrome \\
572.8 & Other sequelae of liver disease \\
573.0 & Other diseases of liver \\
573.1 & Viral hepatitis \\
573.9 & Unspecified disease of liver \\
576.1 & Cholangitis \\
155.0 & Malignant neoplasm of liver \\
\hline
\end{tabular}

The OPCS provided details of all admissions whose discharge coding included any of these diagnoses. $\star \mathrm{ICD}=$ international classification of disease. 


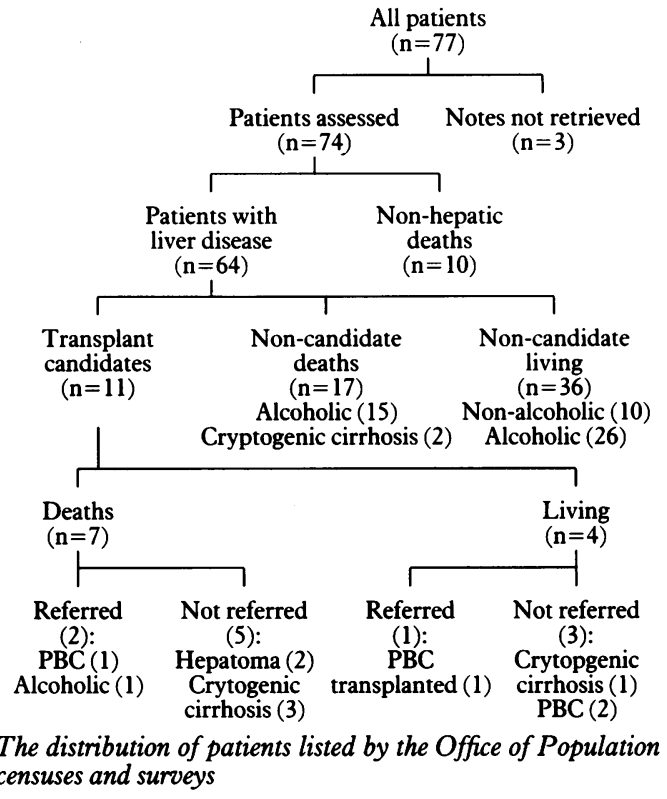

chemical parameters included a serum albumin concentration of less than $25 \mathrm{~g} / 1$ in noncholestatic cirrhosis, or a bilirubin value of 180 $\mu \mathrm{mol} / 1$ in cholestatic liver disease. In alcoholic liver disease, transplant assessment was considered appropriate in the case of sustained abstinence following medical advice. Notes were scrutinised for evidence that these criteria had been fulfilled.

In addition, the accuracy of individual OPCS recorded diagnoses was reviewed.

\section{Results}

The OPCS data showed that 77 patients had been admitted because of liver disease on a total of 113 occasions during the study period. All but three sets of case notes $(96 \%)$ were retrieved. The OPCS diagnoses for the three patients with untraced records were cholangitis (1), alcoholic liver disease (1), and pancreatic carcinoma with hepatorenal syndrome (1). The latter two patients had died.

The remaining 74 sets of case records were reviewed (Figure). These patients were not necessarily under the care of the consultant with an interest in gastroenterology. Sixty four (86\%) could be clearly categorised as suffering from liver disease. The remaining 10 patients $(14 \%)$ seemed to have suffered primarily from nonhepatic disease (carcinomatosis (4), congestive cardiac failure (1), cholelithiasis (2), and septicaemia (3)). All 10 patients died.

Table II shows the disease aetiologies of those 64 patients with liver disease. During the study

TABLE II Aetiologies of liver disease admissions and deaths

\begin{tabular}{lrllc}
\hline Deaths $(n=24)$ & & & Living $(n=40)$ & No \\
\cline { 5 - 6 } Cause & No & & Cause & 26 \\
\hline Alcoholic liver disease & 16 & & Alcoholic liver disease & $6^{\star}$ \\
Primary biliary cirrhosis & 1 & & Primary biliary cirrhosis & 3 \\
Hepatocellular carcinoma & 2 & & Deranged liver function tests & 1 \\
Cryptogenic cirrosis & 5 & & Cryptogenic cirrhosis & Paracetamol overdose \\
& & & Acute hepatitis B & 1 \\
& & & Primary sclerosing cholangitis & 1 \\
\hline
\end{tabular}

^One transplanted.
TABLE III Comparison between OPCS diagnoses and actual diagnosis from case notes for all admissions

\begin{tabular}{|c|c|c|c|c|}
\hline \multirow[b]{2}{*}{ Year } & \multicolumn{2}{|c|}{$\begin{array}{l}\text { Alcohol related } \\
\text { admissions }\end{array}$} & \multicolumn{2}{|c|}{$\begin{array}{l}\text { Non-alcohol related } \\
\text { admissions }\end{array}$} \\
\hline & OPCS & Notes & OPCS & Notes \\
\hline $\begin{array}{l}1987 \\
1988 \\
1989 \\
\text { Total }\end{array}$ & $\begin{array}{r}20 \\
7 \\
15 \\
42\end{array}$ & $\begin{array}{l}33 \\
17 \\
22 \\
72\end{array}$ & $\begin{array}{l}21 \\
28 \\
19 \\
68\end{array}$ & $\begin{array}{r}8 \\
18 \\
12 \\
38\end{array}$ \\
\hline
\end{tabular}

period, $24(38 \%)$ of these died. Alcohol was the cause of liver disease in $16(67 \%)$ of the 24 who died and in $26(65 \%)$ of the 40 patients still alive at the end of the study.

Table III shows the numbers of admissions for alcohol related disease according to the OPCS data and compares these with the diagnoses in the case notes. The OPCS recorded that 42 of 110 (38\%) admissions were alcohol related whereas review of the notes showed figures of $72(65 \%)$. Conversely, OPCS recorded that 68 admissions were not related to alcohol and review of notes showed that only $38(35 \%)$ admissions fell into this category. The same pattern of misclassification was present for each year studied. In $50 \%$ of the misclassified cases the error was to have recorded alcoholic cirrhosis (international classification of disease coding (ICD) 571.2) as ICD 571.5 (cirrhosis - no mention of alcohol). The other erroneous or incomplete classifications were $571.6(3 \%), 571.9(17 \%), 572.2(10 \%)$, $572 \cdot 8(10 \%), 573 \cdot 9(7 \%)$, and $155.0(3 \%)$ (see the figure for codings).

According to our criteria for transplantation, 11 potential transplant candidates were identified from detailed study of case notes (Figure). Of these, seven had died and four were living. Of the seven who were dead, two had been referred for consideration of liver transplantation. One had severe acute alcoholic hepatitis and had continued to drink despite medical advice to the contrary. He did not therefore undergo transplant. The second had primary biliary cirrhosis and died from a variceal bleed while under review. Of the five potential transplant candidates who had not been referred and who had died, two suffered hepatocellular carcinoma (diagnosed during routine monitoring in both instances, one with no further imaging, one with imaging showing tumour localised to the liver) and three had cryptogenic cirrhosis (one of these three patients was referred to a regional unit but not to a transplant unit). Of the four transplant candidates who were alive at the end of the study period, one with primary biliary cirrhosis had been referred and had received a liver transplant. Of the three patients not referred, one had cryptogenic cirrhosis and two had primary biliary cirrhosis. The reasons for non-referral were not given in the notes.

Fifty three patients were not considered to be potential transplant candidates. Seventeen of these had died - 15 with alcoholic liver disease (14 not abstinent, one abstinent patient in whom coexistent disease excluded transplantation), and two patients aged 73 and 86 years with cryptogenic cirrhosis were not fit for transplantation. Of the 36 patients who were alive at the end of the study period and who were not considered for liver transplant, 26 had alcoholic liver disease 
TABLE IV OPCS Liver disease deaths: England and Wales

\begin{tabular}{lrrrrrrrrr}
\hline \multicolumn{10}{c}{ Liver disease deaths 1980-88 } \\
\cline { 2 - 10 }$I C D$ & 1980 & 1981 & 1982 & 1983 & 1984 & 1985 & 1986 & 1987 & 1988 \\
\hline 571.0 & 75 & 73 & 62 & 61 & 59 & 61 & 56 & 55 & 65 \\
571.1 & 54 & 50 & 52 & 42 & 59 & 57 & 64 & 76 & 83 \\
571.2 & 601 & 634 & 637 & 696 & 677 & 620 & 588 & 603 & 645 \\
571.3 & 62 & 65 & 69 & 89 & 171 & 298 & 345 & 413 & 406 \\
$\begin{array}{l}\text { Alcoholic liver } \\
\text { disease deaths total }\end{array}$ & 792 & 822 & 820 & 888 & 966 & 1036 & 1053 & 1147 & 1199 \\
$\begin{array}{l}\text { Non-alcoholic liver } \\
\text { disease deaths total }\end{array}$ & 1683 & 1656 & 1581 & 1495 & 1558 & 1795 & 1710 & 1739 & 1851 \\
\hline
\end{tabular}

ICD = international classification of disease.

(25 not abstinent, one abstinent, but with ischaemic heart disease) and three had primary biliary cirrhosis (in two of these advanced disease was manifest but one had additional psychiatric disease and one advanced cardiopulmonary disease). Three patients had abnormal liver function tests, two had ingested non-fatal paracetamol overdoses, one had acute hepatitis B infection, and one had early primary sclerosing cholangitis.

\section{Discussion}

We found that although up to $11(17 \%)$ patients admitted with liver disease to a district general hospital over a three year period might reasonably have been considered for liver transplantation, only three $(5 \%)$ were actually referred.

The only significant change in criteria for transplantion during the study period was the greater acceptance of alcoholic liver disease as an indication. None of the patients with alcoholic liver disease who were not referred fulfilled the current criteria, however, since they were not abstinent.

Longterm survival in patients who undergo transplantation for hepatocellular carcinoma tends to be shorter than in patients transplanted for cirrhosis, because of disease recurrence. It is noted that the diagnosis in two of the patients who died was hepatocellular carcinoma and it may be that referral of these patients was precluded because of this. However, liver transplantation for hepatocellular carcinoma still has a place in carefully selected patients.

There are inevitable difficulties inherent in a study of this nature. The number of case notes assessed may underestimate the actual number of patients with liver disease, since recognition of cases is dependent upon admissions being classified within the OPCS codes searched, and patients misclassified would not be identified. Some patients with chronic liver disease may have been followed up as outpatients and may not have been admitted to hospital during the study period and, thus, these too would not have been identified. Conversely, patients considered to be appropriate candidates but not referred for transplant, may have had detailed discussion with their physician and declined referral, without mention of this in the case notes. Despite the above difficulties, our results suggest that a significant proportion of potential transplant candidates is not being referred for transplant assessment.

If this population is representative of the UK nationally, a substantial number of patients dying from end stage liver disease is being denied the option of liver transplantation because they are not referred for assessment.

OPCS data recording alcoholic liver disease seem to be very inaccurate. In the three year period under review, 72 admissions resulted from alcoholic liver disease, yet only 42 were recorded as such. OPCS data record only $35 \%$ of deaths from liver disease in Wales as being alcohol related, yet in our district hospital sample $67 \%$ proved to be related to alcohol. It seems likely that there is a similar under recording of alcoholic liver disease in the United Kingdom as a whole. Table III shows the proportions of cases of alcoholic and nonalcoholic liver disease recorded. An apparent rise (almost exclusively in the category ICD 571.3) in alcoholic liver disease has taken place since 1984, probably reflecting a change in legislation. Since July 1984, death from alcoholism has not had to be reported to the coroner. ${ }^{12}$ We suggest that there is still widespread under reporting of alcoholic liver disease, with the greater rather than the lesser proportion of chronic liver disease deaths being alcohol related. The inaccuracy of OPCS data almost certainly reflects inadequate disease coding in hospitals.

In conclusion, this study highlights the fact that some patients are not being referred for consideration of liver transplantation when this might be life saving. It is important that gastroenterologists have a clear knowledge of the criteria for transplant assessment. OPCS data have been shown to represent inaccurately the distribution of alcoholic liver disease. Greater emphasis should be placed on clinical coding detail.

We thank the Office of Population Censuses and Surveys (OPCS) St Catherine's House, London WC2B 6JP for their kind help in the provision of data.

I Starzl TE, Iwatsuki S, Van Thiel DH, Gartner JC, Zitelli BJ, Malatack J, et al. Evolution of liver transplantation. Malatack J, et al. Evolutic

2 Starzl TE, Demetris AJ, Van Thiel DH. Liver Transplantation Parts 1 \& 2. N Engl F Med 1989; 321: 1014-22, 1092-9.

3 Bismuth H, Samuel D, Gugenheim J, Castaing G, Bernuau J, Rueff B, et al. Emergency liver transplantation for fulminan hepatitis. Ann Intern Med 1987; 107: 337-41.

4 Tarter RE, Van Thiel DH, Hegedus AM, Schade RR, Gavale JS, Starzl TE. Neuropsychiatric status after liver transplantation. F L ab Clin Med 1984; 103: 776-82.

5 Iwatsuki S, Gordon RD, Shaw BW Jr, Starzl TE. Role of liver transplantation in cancer therapy. Ann Surg 1985; 202: transp $401-7$

6 Lake JR, Wright LW. Liver transplantation for patients with hepatitis $B$ : what have we learned from our results? hepatitis $\mathrm{B}$ : what have

7 Blumhardt G, Neuhaus P, Bechstein WO, Steffen R, Hopf U, Möller B, et al. Liver transplantation in $\mathrm{HBsAg}$ Positive Möller B, et al. Liver transplantation in
Patients. Transplant Proc 1990; 4: 1517-8.

8 Neuberger JM. Transplantation for alcoholic liver disease. $B M \mathcal{F}$ 1989; 299: 693-4.

9 Maddrey WC, Van Thiel DH. Liver transplantation: an overview. Hepatology 1988; 8: 948-59.

10 Neuberger JM, Gunson BK, Buckels JAC, Elias E, McMaste P. Referral of patients with primary biliary cirrhosis for live transplantation. Gut 1990; 31: 1069-72.

11 O'Grady JG, Williams R. Present position of liver transplantation and its impact on hepatological practice. Gut 1988; 29 . 566-70.

12 Maxwell JD, Knapman P. Effects of coroners' rules on death certification for alcoholic liver disease. BMF 1985; 291: 708 . 
used) increases the rate of healing. ${ }^{+}$On the other hand, the effectiveness of longterm maintenance treatment with sucralfate in healed refractory duodenal ulcer has still to be reported.

Finally, we are in agreement with Moran et al that eradication regimens for $H$ pylori infection should be considered not only for treatment of refractory duodenal ulcers, but also for symptomatic erosive duodenitis, especially if they proved to be resistant to conventional antisecretive treatment.

F PARENTE M LAZZARONI G BIANCHI PORRO Gastrointestinal Unit, L Sacco Hospital, L Sacco Hospital,
Via GB Grassi, 74, 20157 Milan, Italy

l Dang Z, Wang K, Tao J, Zhu L, Hu X. A clinical trial comparing colloidal bismuth subcitrate (DeNol liquid) with sucralfate in the treatment of
peptic ulceration. Clin Trials f 1986; 23: 235-41. 2 Graham DY, Lew GN, Evans DG, Evans DJ, Klein PD. Effect of triple therapy (antibiotic plus bismuth) on duodenal ulcer healing. A randomized controlled trial. Ann Intern Med 1991; 1215: 266-9.

3 Hentschel E, Branstatter G, Dragosics B, Hirschl $A$, Nemec $\mathrm{H}$, Schutze $\mathrm{K}$, et al. Effect of A, Nemec H, Schutze K, et al. Effect of ranitidine and amoxicillin plus metronidazole on the eradication of Helicobacter pylori and the recurrence of duodenal ulcer. $N$ Engl F Med
1993 ; 328: 308-12. 1993, 328: 308-12.

Bianchi Porro G, Parente F. Duodenal ulcers resistant to $\mathrm{H}_{2}$-blockers: an emerging therapeutic problem. Scand f Gastroenterol 1988; 24 (suppl 153): 81-8.

\section{BOOK REVIEW}

Inhibition of Gastric Secretion. Baillière's Clinical Gastroenterology. Vol 7. No 1. Edited by N D Yeomans. (Pp 194; illustrated; £27.50.) London: Baillière Tindall, 1993.

This addition to the excellent series of Baillière's Clinical Gastroenterology is devoted to 'Inhibition of gastric acid secretion', with chapters on the mechanism of gastric secretion; the pharmacology of gastric secretion and its measurement; plus reviews of the two principal types of anti-secretory drugs $\left(\mathrm{H}_{2}\right.$ receptor antagonists and proton pump blockers) as well as gastric surgery. Three chapters are devoted to potential hazards of gastric secretory inhibition. There is not much overlap between chapters and the contributions are generally consistently comprehensive and well presented. Some of the chapters are not as well focused as others, so that the initial chapter on the cellular biology of gastric secretion is not really a useful analysis of the processes entailed in the production of gastric juice - a topic discussed much better in the chapter devoted to the basic pharmacology of gastric secretory inhibition. As expected, the chapter on measurement of gastric secretion by Pounder and Fraser is the best in the book.

The therapeutic analysis is unbalanced, so that $\mathrm{H}_{2}$ receptor antagonists are given 10 pages of text while omeprazole receives 24 pages. Moreover, the book is not really all that up to date, because in the five main chapters, only $23 \%$ of the references have been published since 1990 . Clearly, the inhibition of a process that has taken millions of years to evolve may be associated with risk. As one of the principal functions of gastric juice is to provide facilities for sterilising the intestinal contents at the proximal end of the alimentary tract, the effect of gastric inhibition on the gastric flora is important and has been satisfactorily reviewed, highlighting our làck of knowledge of this important topic. The chapter on the very important gastric mucosal changes that accompany gastric secretory inhibition repeats what has been written by the author on many previous occasions. A more critical and impartial assessment is desirable in future.

Obviously, gastric secretory inhibition must be long term because the peptic diseases are chronic ones. Hence the long term safety of the different types of gastric secretory inhibitors must be carefully monitored. Because the results of the long term toxicological studies in animals have been disregarded by many regulatory authorities, long term prospective surveillance studies are urgently required. Professor Langman's review of post-marketing surveillance, based on extensive personal studies, depressingly emphasises the difficulties of such studies and raises important issues. Further volumes, devoted to gastric secretory inhibition, are necessary and will be welcome (and will be required despite the current obsession with commensal organisms in the stomach).

K G WORMSLEY

If you wish to order or require further information regarding the titles reviewed here, please write to or telephone the BMJ Bookshop, PO Box 295, London WC1H 9JR. Tel: 071383 6244. Fax: 071383 6662. Books are supplied post free in the UK and for BFPO addresses. Overseas customers should add $15 \%$ for postage and packing. Payment can be made by cheque in sterling drawn on a UK bank or by credit card (Mastercard, Visa, or American Express), stating card number, expiry date, and full name. (The price and availability are occasionally subject to revision by the Publishers.)

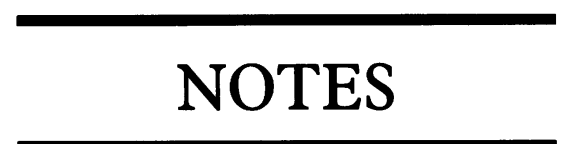

\section{Sir Francis Avery Jones BSG Research} Award 1994

Applications are invited by the Education Committee of the British Society of Gastroenterology who will recommend to Council the recipient of the 1994 Award. Applications (Fifteen copies) should include:

(1) A manuscript (2 A4 pages only) describing the work conducted.

(2) A bibliography of relevant personal publications.

(3) An outline of the proposed content of the lecture, including title.

(4) A written statement confirming that all or a substantial part of the work has been personally conducted in the United Kingdom or Eire.

Entrants must be 40 years or less on 31 December 1994 but need not be a member of the BSG. The recipient will be required to deliver a 40 minute lecture at the Spring
Meeting of the Society in 1994. Applications (Fifteen copies) should be made to: The Honorary Secretary, BSG, 3 St Andrew's Place, London NW1 $4 \mathrm{LB}$ by 1 December 1993.

\section{European Postgraduate Gastro-Surgical} School

A postgraduate course Update in Digestive Oncology will be held in Amsterdam on 16-17 December 1993.

An International Congress - New trends in the diagnosis and treatment of oesophageal cancer will be held in Amsterdam on 17-18 February 1994. Further information for both these events from: Managing Director European Postgraduate Gastro-Surgical School, Room 109.3, Academic Medical Center, Meibergdreef 9, $1105 \mathrm{AZ}$ Amsterdam, The Netherlands. Tel: 3120 5663926; fax: 3120 6914858.

\section{Therapeutic endoscopy}

The 3rd International Workshop on Therapeutic Endoscopy and Gastroenterology will be held on 4-7 March 1994 in Beijing, China. Further information from: Dr Sydney Chung, Combined Endoscopy Unit, Prince of Wales Hospital, Shatin, NT, Hong Kong. Tel: 852 6362233; fax: 8526350075 .

\section{Cholestasis and related disorders}

The International Meeting on Cholestasis and related disorders will be held in Florence on 23-26 March 1994. Further information from: Organising Secretariat, OIC srl, Via A La Marmora, 24, 50121 Florence, Italy. Tel: 3955 5000 631; fax: 39555702 27/50 01912 .

\section{Gastrointestinal hormones}

The 10th International Symposium on Gastrointestinal Hormones will be held 27-31 August 1994 in Santa Barbara, California. Further information from: Joyce M Fried, Symposium Administrator, UCLA School of Medicine, Office of the Dean, 10833 Le Conte Avenue, Los Angeles, California 90024-1722, USA. Fax: 310 206-5046.

\section{European Association for the Study of the} Liver

The 29th Annual Meeting of the European Association for the Study of the Liver (EASL) will be held in Athens on 7-10 September 1994. Further information from: Professor G Tiniakos, c/o Olympic Sun, International Congress Organisers, 7, Voulis Str, 10562 Syntagma, Athens, Greece. Fax: 301 3229149, 3225428.

\section{Correction}

The authors apologise for an error in Table IV line 1 in their paper (Gut 1992; 33: 1397-9). The numbers of deaths should be: ICD 198019811982198319841985198619871988

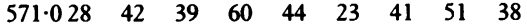

